WellBeing International

WBI Studies Repository

$10-2004$

\title{
Evolution of Nociception in Vertebrates: Comparative Analysis of Lower Vertebrates
}

Lynne U. Sneddon

University of Liverpool

Follow this and additional works at: https://www.wellbeingintlstudiesrepository.org/acwp_vsm

Part of the Animal Studies Commons, Comparative Psychology Commons, and the Other Animal

Sciences Commons

\section{Recommended Citation}

Sneddon, L. U. (2004). Evolution of nociception in vertebrates: comparative analysis of lower vertebrates.

Brain Research Reviews, 46(2), 123-130.

This material is brought to you for free and open access by WellBeing International. It has been accepted for inclusion by an authorized administrator of the WBI Studies Repository. For more information, please contact wbisr-info@wellbeingintl.org.

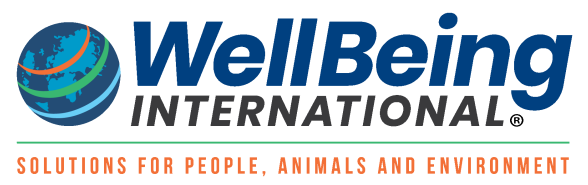




\title{
Evolution of nociception in vertebrates: Comparative Analysis of Lower Vertebrates
}

\author{
Lynne U. Sneddon \\ University of Liverpool
}

\section{KEYWORDS}

Nociceptors, fish, C fibres, pain

\begin{abstract}
Nociception is an important sensory system of major fundamental and clinical relevance. The nociceptive system of higher vertebrates is well studied with a wealth of information about nociceptor properties, involvement of the central nervous system and the in vivo responses to a noxious experience are already characterised. However, relatively little is known about nociception in lower vertebrates and this review brings together a variety of studies to understand how this information can inform the evolution of nociception in vertebrates. It has been demonstrated that teleost fish possess nociceptors innervated by the trigeminal nerve and that these are physiologically similar to those found in higher vertebrates. Opioid receptors and endogenous opioids are found in the brain and spinal cord of the fishes and morphine blocks avoidance learning using electric shock as well as reducing nociceptive behavioural and physiological responses to noxious stimulation. Comparative analysis of the fishes and higher vertebrates show that fish possess less $C$ fibres than higher vertebrates. The electrophysiological properties of fish nociceptors are almost identical to those found in higher vertebrates suggesting the evolution of these properties occurred before the emergence of the fish groups.
\end{abstract}

\section{Introduction}

Nociception is the detection of potentially injurious stimuli and gives rise to pain which usually has not only a sensory component but is also an emotional experience. From both a clinical and animal welfare perspective, studies have sought to understand the occurrence, mechanisms and consequences of potentially painful events to minimise and alleviate any pain suffered by the individual. Most research has been conducted on mammalian models since these are directed at understanding human pain (e.g. Ref. [17]). Therefore, there is a wealth of information regarding nociception in mammalian systems (review in Ref. [29]), however, more recently non-mammalian vertebrates, amphibian and avian models, have been extensively studied (e.g. amphibians [52]; birds [14]). Very little is known about the lower vertebrate groups and their capacity for nociception. The purpose of this review is to firstly examine the evidence for nociception in the agnathans (lampreys and hagfish); the elasmobranchs or cartilaginous fish (sharks, skates, rays) and the teleost or bony fish and then compare this to studies in higher vertebrates to enlighten the evolutionary differences between the lower and higher vertebrates. 


\section{The criteria for nociception and pain}

Many scientists have discussed at length the criteria an animal group has to meet to fulfil the requirements for nociception and pain. Obviously, all animal groups possess nociceptors and many invertebrate models have yielded important insights into nociceptor function (e.g. the land snail [20]). However, pain is a much more complicated phenomenon and since animals cannot tell us they are in pain, these criteria have been drawn up to provide a guide as to whether the animal might be capable of experiencing pain. These criteria are based on Bateson's [2] criteria.

- Nociceptors

- Brain structures

- Pathways to higher brain structures

- Opioid receptors and substances

- Analgesics reduce nociceptive response

- Avoidance learning

- Suspension of normal behaviour

Each criterion shall be taken in turn to assess whether lower vertebrates fulfil these criteria and are viable models for nociception studies.

\subsection{Nociceptors}

Nociceptors are associated with free nerve endings and are usually of two fibre types, small myelinated A-delta fibres and smaller unmyelinated $C$ fibres [29]. In mammalian systems, $C$ fibres can range in diameter from 0.2 to $3.0 \mu \mathrm{m}$ whereas the larger A-delta fibres range from 2 to $14 \mu \mathrm{m}$ [29]. The conduction velocity of the smaller $C$ fibres in mammals is approximately 0.3 to $1.2 \mathrm{~m} / \mathrm{s}$ whereas A-delta conduct at a speed of 5 to $30 \mathrm{~m} / \mathrm{s}$. The teleost fish body is covered in free nerve endings of unknown function [51] yet few studies have looked at the anatomy for the presence of A-delta or C fibres in this group. One such study on the rainbow trout, Oncorhynchus mykiss, examined the trigeminal nerve and found both fibre types in all of the three main branches of the trigeminal nerve [42]. These fibres matched the size range found in higher vertebrates (Fig. 1). Most other studies on the anatomy of peripheral nerves have examined elasmobranch fish and have discovered a lack of $C$ fibres although A-delta fibres are present (e.g. stingray, Dasyatis sabina; spotted eagle ray, Aetobatus narinari; cownose ray, Rhinoptera bonasus; longtailed ray, Himantura sp. $[7,25,47])$. Electrophysiological studies also failed to find slowly adapting mechanoreceptors, a property of mammalian nociceptors, or receptors that responded to temperature increases in the stingray $[7,47]$. This is in contrast to studies on the rainbow trout where the majority of receptors innervated by the trigeminal nerve were slowly adapting as well as 22 receptive fields from a total of 58 responsive to noxious heat (Fig. 2 [43,45]). Out of these 22 receptive fields, 18 also responded to application of acetic acid and could be classified as polymodal nociceptors whereas the remaining 4 did not respond to acid and could be classified as mechanothermal nociceptors [43]. Therefore, studies in elasmobranchs have failed to find nociceptors, yet teleost fish appear to possess unmyelinated fibres and nociceptors. The oldest living ancestor of the fishes, the lamprey, Petromyzon marinus, has only unmyelinated fibres and electrophysiological recordings did find slowly adapting receptors that responded to noxious heat and were, therefore, possibly nociceptive [30].

\subsection{Brain structures}

The fishes have the necessary brain areas for nociceptive processing to occur (e.g. pons, medulla, thalamus), however, one area of debate is the cortex. The most highly evolved vertebrates, humans and primates, have the most developed cortex with the evolution of the neocortex. As we descend the 
evolutionary tree of vertebrates (Fig. 3), the cortex becomes less differentiated but fishes do appear to possess a rudimentary cortex area. In the elasmobranchs, this telencephalic area is characterised by large well-defined cell groups with a well-developed thalamic input [34]. In teleosts, this rudimentary cortex is better developed with the hemispheric zones possessing complex projections to the diencephalon and midbrain [34]. Work in this field is incomplete but should be directed at understanding the similarities between amniotes and the fishes to understand the evolutionary basis of telencephalon development.

Fig. 1. Section of the maxillary branch of the trigeminal nerve of the rainbow trout showing the presence of A-delta and C fibres [42].

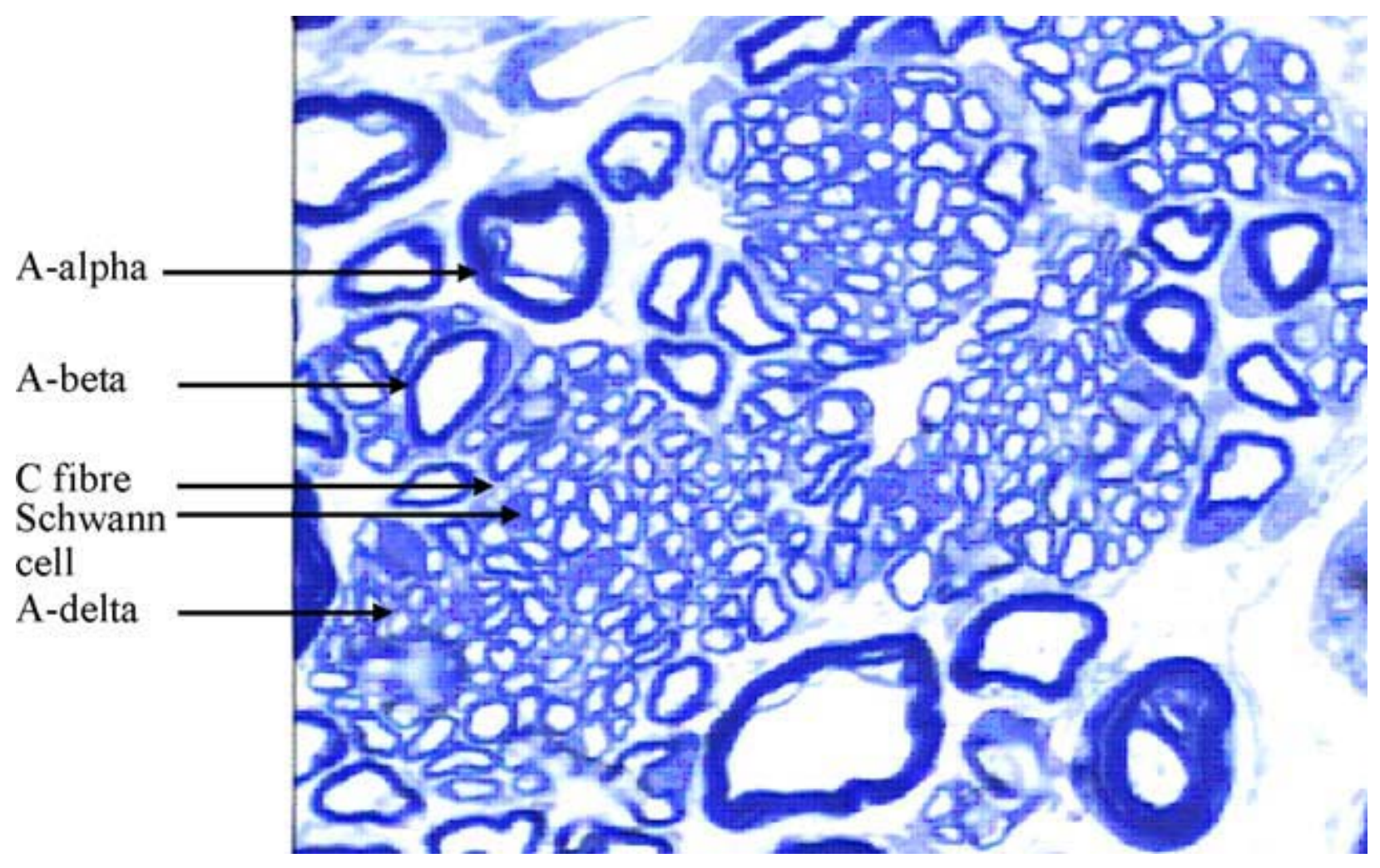

\subsection{Pathways to higher brain structures}

The major tracts involved in nociceptive processing and relaying information to the brain are the trigeminal tract conveying information from the head and the spinothalamic tract conveying information from the rest of the body. Both tracts have been extensively studied in lower vertebrates groups. In an agnathan, the Pacific hagfish, Eptatretus stouti, horseradish peroxidase tracing demonstrated that the trigeminal nerve descended through the medulla to the rostral spinal cord in a similar manner seen in higher vertebrates [39]. The trigeminal tract also ascended into the mesencephalic tectum although distinct mesencephalic and descending nuclei of the trigeminal system are yet to be found in this group [39]. This was also the case in the lamprey [33]. However, studies in teleost fish have shown that there are distinct nuclei namely the mesencephalic nucleus and descending nucleus (carp, Cyprinus carpio [28]; sturgeon, Acipenser oxyrhynchus [32]). The appearance of the two trigeminal nuclei in the teleosts but not in the predecessors of the fishes suggests that these nuclei evolved after the agnathans. However, these nuclei are present in an elasmobranch, the dogfish, Scyliorhinus canicula [1,38], and thus 
must have evolved between the agnathans and the emergence of the fishes. In the carp, the trigeminal clearly projects to the thalamus as it does in higher vertebrates, therefore, this pathway is present in lower vertebrates.

Fig. 2. A polymodal nociceptor innervated by the trigeminal nerve of the rainbow trout responding to mechanical $(A)$, thermal (B) and chemical stimulation (C; $1 \%$ acetic acid). The receptor is slowly adapting to mechanical stimulation $\left(\mathrm{A}\right.$; ON indicates application of stimulus), has a thermal threshold of $58{ }^{\circ} \mathrm{C}(\mathrm{B})$ and responds to application of a drop of acetic acid onto the receptive field (C) [43].
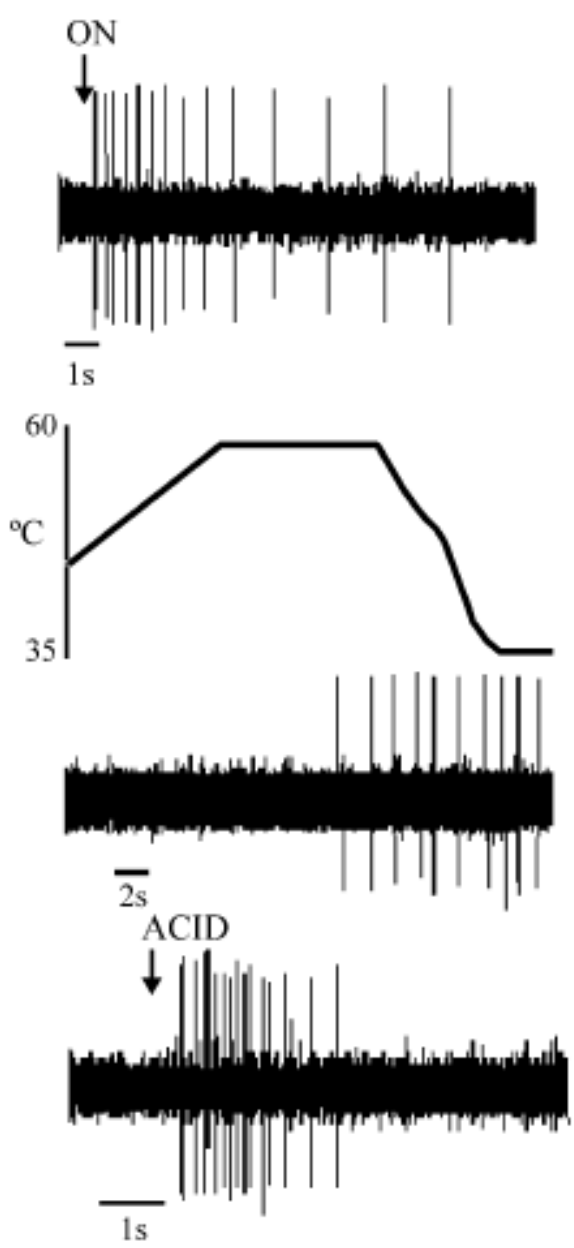

The spinal cord of elasmobranchs has been extensively studied showing that the grey matter of the spinal cord can be divided into seven laminae [19]. The first laminae is cell dense and occupies the major part of the dorsal horn and corresponds to lamina 1 and the substantia gelatinosa of the spinal cord of mammals, birds and reptiles. Ascending fibres in the spinal cord of the nurse shark, Ginglymostoma cirratum, reach the reticular formation and also project to the dorsal motor nucleus of the vagus, the medulla oblongata, the central brain stem, the cerebellar cortex, the cerebellar nucleus, the nucleus intercollicularis, the mesencephalic tectum and the thalamus [9]. Within the reticular formation of two elasmobranch species, the thornback guitarfish (Platyrhinoidis triseriata) and the horn shark (Heterodontus francisci), there are 19 reticular nuclei with spinal projections indicating that the elasmobranch reticular formation is complexly organised into many of the same nuclei as found in higher vertebrate groups [8]. When examining the distribution of immunoreactivity to serotonin, substance $\mathrm{P}$, somatostatin, calcitonin gene-related peptide, neuropeptide $Y$ and bombesinin in a variety of elasmobranch species, the distribution is strikingly similar 
to mammals. Therefore, the elasmobranch groups have the same basic components of ascending spinal projections [9]. This has also been confirmed in studies on teleost fish (e.g. sea robin, Prionotus carolinus [12]; channel catfish, Ictalurus punctatus [16]).

Fig. 3. A hypothetical linear evolutionary diagram showing the cortical development from fishes to mammals [34].

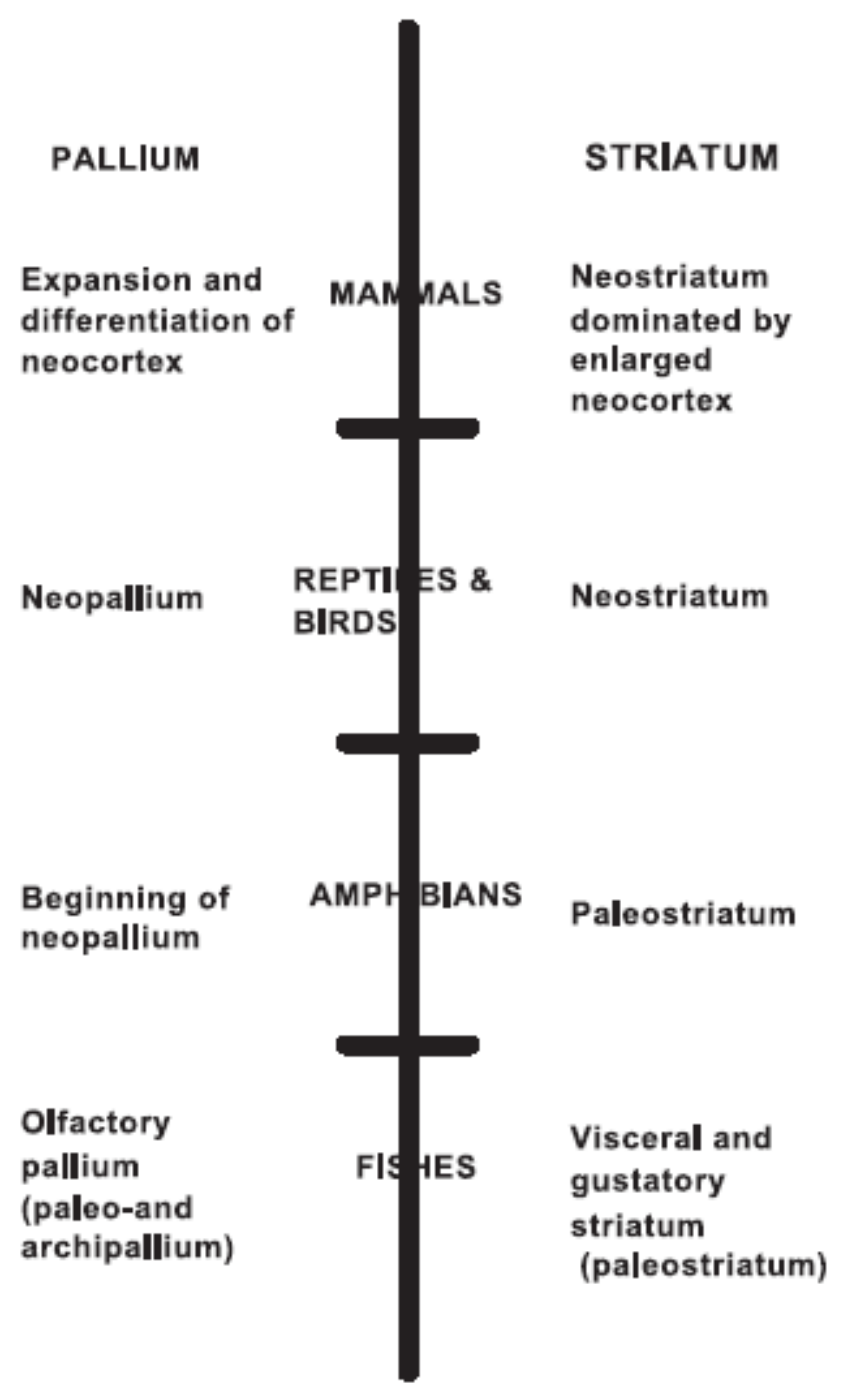

\subsection{Opioid receptors and substances}

The possession of opioid receptors and endogenous opioids and enkephalins is thought to be a crucial factor in determining whether nociception can occur. In mammals, opiate receptors and substances are located particularly in the regions involved in the processing of nociceptive and pain information e.g. the spinal cord, the raphe nucleus, the reticular formation, the periaquaeductal gray and the thalamus [41]. In non-mammalian vertebrates, encephalin-like immunoreactivity has been demonstrated in birds [36], reptiles [35] and amphibians [31]. Opiate receptors have been found in fish [6] as well as encephalin-like substances in various brain areas of goldfish [11,40]; catfish [11], African lungfish [37] and rainbow trout [49]. Within the brain, enkephalins show a similar distribution pattern to that seen in higher vertebrates 
[50]. In the spinal cord, enkephalin-like immunoreactivity is most dense in the superficial portion of lamina A which is thought to be similar to the substantia gelatinosa of mammals [47]. Therefore, a comparable distribution of opiate receptors and substances is found in both elasmobranchs and teleosts that are seen in higher animals.

Fig. 4. (A) The mean frequency of rubbing performed by rainbow trout injected subcutaneously with $0.1 \%$ acetic acid (Acid) and fish also injected with the acid but administered with morphine (Acid-Morphine). (B) The mean respiration rate (rate of ventilation of gills) of handled controls (Control), saline injected fish (Saline), control fish administered with morphine (Morphine), acid injected fish (Acid) as well as acid injected fish that were treated with morphine (AcidMorphine) [44].

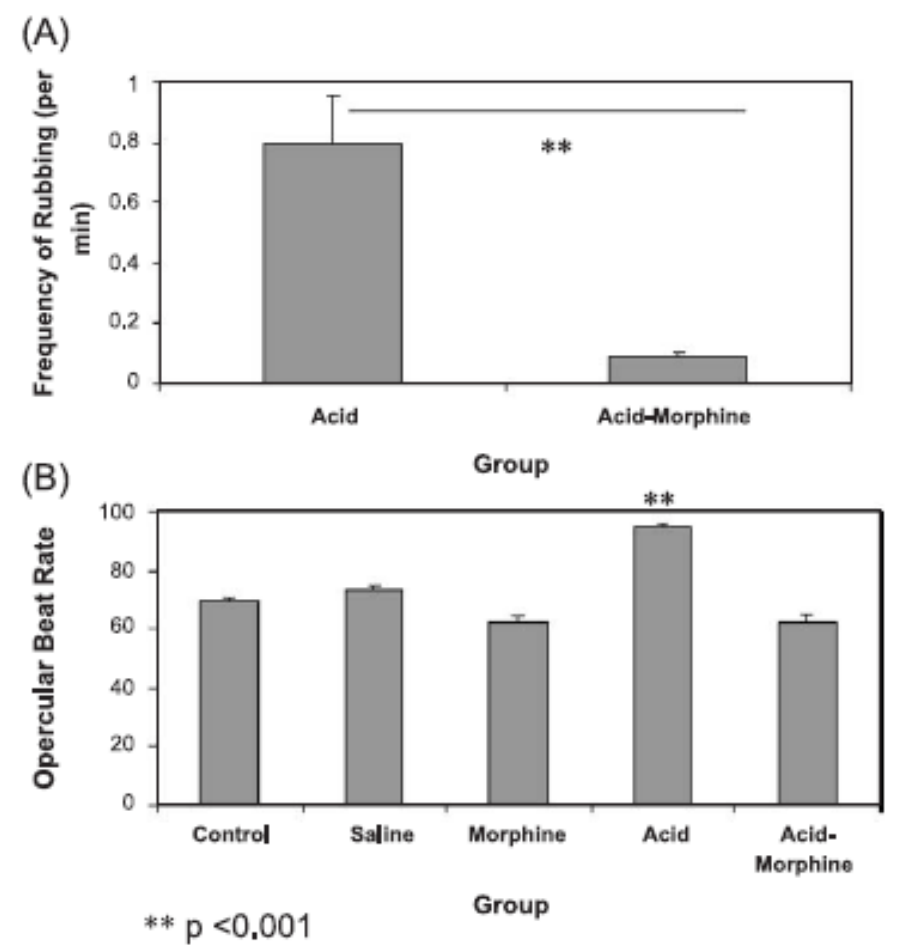

\subsection{Analgesics reduce nociceptive response}

Very little is known about analgesia in fish since it has only been recently found that they possess nociceptors $[42,43]$. The few studies that are available address the effects of morphine. The in vivo responses to subcutaneous acetic acid injection were quantified in the rainbow trout. These adverse behavioural responses included the rubbing of the affected area which was not seen in handled controls or saline-injected fish [44,45]. When morphine was administered to fish injected with acid, there was a dramatic reduction in this rubbing behaviour (Fig. 4A). As well as affecting behavioural output, the enhanced respiration rate seen in acid injected fish was also ameliorated by morphine (Fig. 4B). Therefore, morphine appears to reduce nociceptive responses in teleost fish. This has not been repeated in any of the other lower vertebrate groups.

\subsection{Avoidance learning}

Using negative conditioning as a test paradigm, Ehrensing et al. [10] conditioned goldfish to avoid electric shock. When morphine was administered the fish failed to learn and a high voltage of electric shock was needed to elicit a response whereas when the antagonists, MIF-1 and naloxone were used, avoidance 
was generated at a much lower voltage (Fig. 5). A few other studies have shown that teleost fish are capable of associating a stimulus with a noxious experience and learning to avoid it subsequently $[4,5]$.

\subsection{Suspension of normal behaviour}

The final criterion that has to be fulfilled is the interference of normal behaviour whilst enduring a noxious event. This is an indirect measurement of how the animal responds to the experience and to try and gauge whether the animal is suffering pain rather than a simple nociceptive reflex. If the animal's normal behaviour is adversely affected and this experience is painful to humans, then it is likely to be painful to the animal. This is a very subjective method but currently is the primary method available for assessing animal pain [2]. When rainbow trout were given subcutaneous injections of acetic acid and bee venom (algesics), they showed an enhanced respiration rate for approximately $3 \mathrm{~h}$ as well as performance of anomalous behaviours and during this period they did not feed [45]. Handled controls and saline-injected fish did not perform these anomalous behaviours and did not show such a great increase in respiration rate and began feeding around $80 \mathrm{~min}$ after treatment. The noxiously stimulated fish only resumed feeding once the behavioural and physiological affects of the bee venom and acetic acid had subsided (180 $\mathrm{min}$ ). Further testing showed that noxiously stimulated trout did not show an appropriate fear response to a fear-causing stimulus and it was suggested that the noxious experience dominated attention and the fish could not divert attention to the fear stimulus [46]. This could be interpreted as the noxious experience being the imperative in this test paradigm and many clinical studies have shown human do not perform as well on other tasks when in pain [21]. Therefore, the studies in the rainbow trout demonstrate that the negative effects of a noxious experience are complicated in nature suggesting higher processing is involved and thus there is the potential for pain perception in this teleost fish.

Fig. 5. The voltage of electric shock needed for an avoidance response in goldfish administered with morphine or the opioid antagonists MIF-1 and naloxone [10].

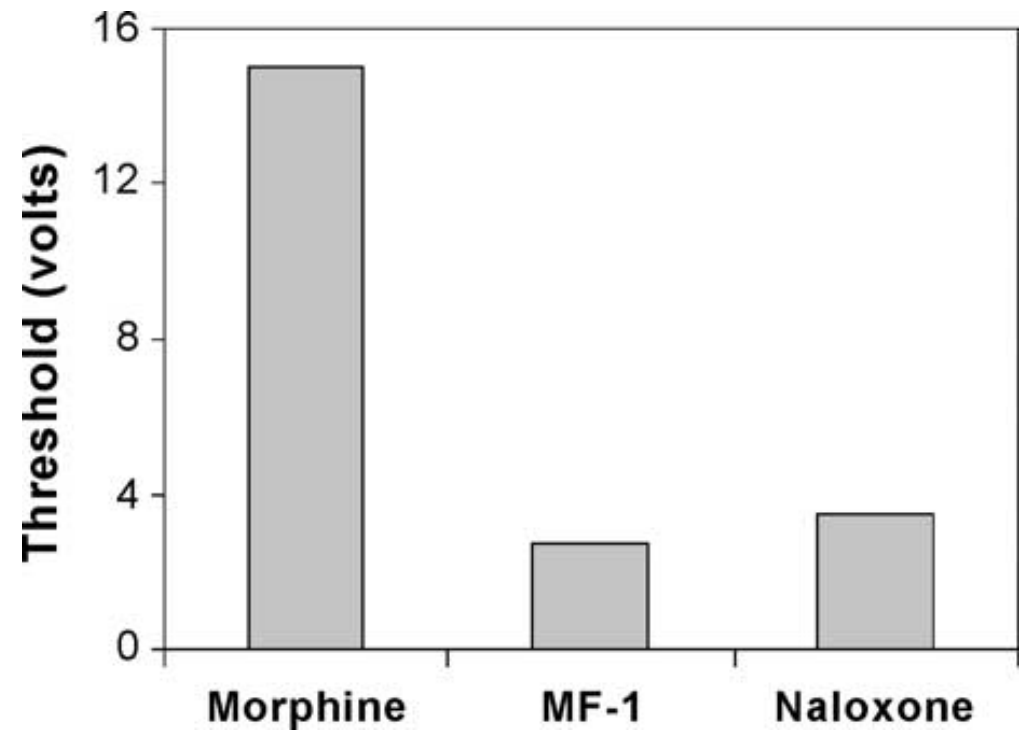

The lower vertebrates, and specifically the teleost fish since most studies have examined this group, do appear to fulfil the criteria for nociception and possibly pain perception, therefore, they are a viable model for research of this important sensory system. Although the most appropriate model should be used for any study, fish do have some advantages over mammalian models. Fish are economically less expensive, low maintenance, high numbers of fish can be kept in the laboratory aquarium, many species 
breed easily under laboratory conditions and fish such as zebrafish can become mature in 7 months, breed every 3 months with a progeny of around 100 offspring. External fertilisation reduces the need for surgery to produce transgenic lines. The optical clarity of the embryo and developing larvae make injections to the nervous system easier and gene expression can be followed in vivo with the use of reporter genes such as green fluorescent protein (GFP). With all these advantages, the lower vertebrates should be considered for fundamental and evolutionary studies of nociception and pain. The next section of the review shall examine nociceptor properties in the lower vertebrates to address the question of what they can tell us about the evolution of this sensory system.

\section{Nociceptor properties}

\subsection{Anatomical studies}

Both A-delta and $\mathrm{C}$ fibres were found in the rainbow trout trigeminal nerve and the diameter of these fibres was similar to those found in higher vertebrates [42]. However, there were much fewer $C$ fibres in the fish nerve than is found in higher animals. Typically, C fibres comprise $50 \%$ to $65 \%$ of total fibre type in amphibians, birds and mammals [29], yet the teleost fish had only $4 \% \mathrm{C}$ fibres within the trigeminal. Adelta fibres are normally outnumbered 4 to 1 by $C$ fibres in mammals [29] but A-delta fibres comprise 25\% of fibre type in the fish. This reduced number of $C$ fibres in fish as opposed to the high number in mammals may be explained by the advance onto land in evolution. Terrestrial vertebrates may be subject to a greater chance of injury due to gravitational forces, noxious gases and extremes of temperature whereas in the aquatic environment, buoyancy counteracts gravity, chemicals can be diluted and there are generally no great fluctuations in temperature as are seen on land. So perhaps the fish has not devoted as much neural wiring to a nociceptive system as the terrestrial vertebrates have who have a much more comprehensive system to deal with the increased risk of damage. This hypothesis remains to be tested and it would be fascinating to look at aquatic mammals to examine whether they possess a different $\mathrm{C}$ fibre system to the land vertebrates.

The agnathans have no myelination whereas the elasmobranch species studied appear to have only myelinated fibres and nociceptors have not been identified using electrophysiology [25]. However, in a teleost fish, both C fibres and polymodal nociceptors have been characterized [42,43]. This may represent an evolutionary divergence between the teleost and elasmobranch lineages where elasmobranchs have lost unmyelinated fibres and teleosts have retained these and of course the teleost group is thought to give rise to the higher vertebrates in evolution. Future studies should expand the neuroanatomical study of different groups of agnathans, elasmobranchs and teleost fish to build a picture of the evolutionary anatomical relationships of these lower vertebrate groups.

\subsection{Electrophysiological properties}

Nociceptors are generally characterised by their slowly adapting response to mechanical stimulation and response to noxious heat $\left(>40{ }^{\circ} \mathrm{C}\right)$ and they may also respond to noxious chemicals [29]. In the lamprey, the predecessor of the fishes, receptive fields were found which gave a slowly adapting response to mechanical stimulation, responded to noxious heat and to damaging stimuli [30]. This work has not been followed up in this species but studies have failed to find nociceptors in elasmobranchs $[7,25]$. Investigations have mostly been conducted on a teleost, the rainbow trout, and have shown the presence of both polymodal nociceptors and mechanothermal nociceptors on the head of the fish [43]. Many nociceptor properties are common to this fish and higher vertebrates. For example, the diameter of the receptive fields ranged from 1.6 to $9 \mathrm{~mm}$ which is a similar diameter found in birds [15] and mammals [48]; the fish nociceptors have large, broad action potentials with slow depolarisation as also seen in 
mammalian models [13,27]; and finally the conduction velocity of the fish nociceptors are within the mammalian A-delta and C fibre range [29].

Table 1. Electrophysiological properties of A-delta nociceptors in a fish [43], a snake [26], and a mouse [27]

\begin{tabular}{|lccc|}
\hline & Fish & Snake & Mouse \\
\hline Conduction velocity $(\mathrm{m} / \mathrm{s})$ & $0.7-5.5$ & 3.8 & $0.7-5.7$ \\
AP amplitude $(\mathrm{mV})$ & $10-90$ & 91 & 70.89 \\
AP duration $(\mathrm{ms})$ & $0.8-2.4$ & 2.4 & $0.7-2.8$ \\
AHP amplitude $(\mathrm{mV})$ & $1.8-5.5$ & 11.9 & $6-12$ \\
$\mathrm{~d} V / \mathrm{d} t_{\text {max }}(\mathrm{V} / \mathrm{s})$ & $63-226$ & 182 & $115-291$ \\
\hline $\begin{array}{l}\text { Mean values are shown for conduction velocity, action potential (AP) } \\
\text { amplitude and duration, afterhyperpolarisation (AHP) } \\
\text { maximum rate of depolarisation (dV/dt } t_{\text {max }} \text { ). }\end{array}$ & & \\
\hline
\end{tabular}

There are some interesting differences between fish and higher animals. Mechanical thresholds are much lower in the fish nociceptors with some being stimulated below $0.1 \mathrm{~g}$ [43]. Many mammalian skin nociceptors need a minimum pressure of $0.6 \mathrm{~g}$ before they are stimulated [29], yet the fish nociceptors appear to be much more sensitive with thresholds this low only seen in mammalian corneal nociceptors $[3,27]$. The rainbow trout study also demonstrated that the majority of polymodal nociceptors were A-delta fibres, however, in the higher vertebrate skin it is usually C fibres that act as polymodal nociceptors [24]. Polymodal A-delta fibres are usually found in oral mucosa [48], skeletal muscle [22] and visceral organs $[18,23]$. The nociceptors of these areas are mainly polymodal possibly due to the various aqueous and hard substances that they come into contact with that provide a mixture of mechanical, chemical and thermal stimulation. Fish inhabit an aqueous world so perhaps this is why the majority of nociceptors on the skin are polymodal [43]. When comparing the electrophysiological properties of the fish nociceptors to those found on the snake head [26] and those found on the mouse cornea [27], most of the properties are strikingly similar (Table 1). Characteristics such as rate of firing, maximum rate of depolarisation and afterhyperpolarisation amplitude duration are slower but this is probably due to the temperature difference between the cold-blooded fish at $18{ }^{\circ} \mathrm{C}$ and the mammal at $37^{\circ} \mathrm{C}$. This temperature difference may mean that the fish physiological characteristics are two to four times slower. Since the teleost fish shares common properties with both a reptile and a mammal, this suggests that these characteristics evolved in a predecessor of the teleost group and, therefore, the electrophysiological properties of nociceptors in the agnathans warrants further investigation to discern whether these properties are also present in this group.

Many of the anatomical and electrophysiological properties of the teleost fish are very similar to that found in higher vertebrate groups. Work on lower vertebrates is in its infancy compared with other animals and by studying the fishes we can gain an insight into the evolution of this important sensory system. However, much remains to be done and by characterising nociceptors in more detail we shall gain an insight into the comparative aspects of nociception. Studies should not be restricted to anatomy and electrophysiology, but should also assess the involvement of the brain, changes at the molecular level and also investigating the behavioural responses to noxious stimulation to include the use of analgesics. 
It can be concluded that fish are a viable model for investigating the fundamental attributes of nociception in future studies.

\section{Acknowledgements}

LUS is supported by a NERC fellowship and a BBSRC research grant. Fig. 1 reprinted from Neuroscience Letters, 312, L.U. Sneddon, Anatomical and electrophysiological analysis of the trigeminal nerve of the rainbow trout, Onchorynchus mykiss, 167-171, Copyright (2002), with permission from Elsevier. Fig. 2 reprinted from Brain Research, 972, L.U. Sneddon, Trigeminal somatosensory innervation of the head of the rainbow trout with particular reference to nociception, 44-52, Copyright (2003), with permission from Elsevier. Fig. 3 adapted and reprinted, with permission, from the Annual Review of Neuroscience, Volume 4 C1981 by Annual Reviews www.annualreviews.com. Fig. 5 reprinted from Pharmacology, Biochemistry and Behaviour, Vol. 17, pp. 757-761, Ehrensing et al. with permission from Elsevier.

\section{References}

[1] R. Anadón, P. Molist, I. Rodríguez-Moldes, J.M. Lo'pez, I. Quintela, M.C. Cerviňo, P. Barja, A. González, Distribution of cholineacetyltransferase immunoreactivity in the brain of an elasmobranch, the lesser spotted dogfish (Scyliorhinus canicula), J. Comp. Neurol. 420 (2000) 139- 170 .

[2] P. Bateson, Assessment of pain in animals, Anim. Behav. 42 (1992) 827- 839.

[3] C. Belmonte, J. Gallar, Corneal nociceptors, in: C. Belmonte, F. Cervero (Eds.), Neurobiology of Nociceptors, Oxford University Press, Oxford, UK, 1996, pp. 146- 183.

[4] J.J. Beukema, Angling experiments with carp (Cyprinus carpio L.): II. Decreased catchability through one trial learning, Neth. J. Zool. 19 (1970) 81-92.

[5] J.J. Beukema, Acquired hook avoidance in the pike Esox lucius L. fished with artificial and natural baits, J. Fish Biol. 2 (1970) 155-160.

[6] M.C. Buatti, G.W. Pasternak, Multiple opiate receptors: phylogenetic differences, Brain Res. 218 (1981) 400- 405.

[7] R.E. Coggeshall, R.B. Leonard, M.L. Applebaum, W.D. Willis, Organisation of peripheral nerves of the Atlantic stingray, Dasyatis sabina, J. Neurophysiol. 41 (1978) 97-107.

[8] W.L.R. Cruce, S.L. Stuesse, R.G. Northcutt, Brainstem neurons with descending projections to the spinal cord of two elasmobranch fishes: thornback guitarfish, Platyrhinoidis triseriata, and horn shark, Heterodontus francisci, J. Comp. Neurol. 403 (1999) 534- 560.

[9] S.O.E. Ebbesson, K.C. Hodde, Ascending spinal systems in the nurse shark, Ginglymostoma cirratum, Cell Tissue Res. 216 (1981) 313- 331.

[10] R.H. Ehrensing, G.F. Michell, A.J. Kastin, Similar antagonism of morphine analgesia by MIF-1 and naxolone in Carassius auratus, Pharmacol. Biochem. Behav. 17 (1982) 757- 761.

[11] T.E. Finger, Fish that taste with their feet: spinal sensory pathways in the sea robin, Prionotus carolinus, Biol. Bull. 161 (1981) 154- 161. 
[12] T.E. Finger, Ascending spinal systems in the fish, Prionotus carolinus, J. Comp. Neurol. 422 (2000) 106- 122.

[13] R. Gallego, The ionic basis of action potentials in petrosal ganglion cells of the cat, J. Physiol. 342 (1983) 591-602.

[14] M.J. Gentle, Pain in birds, Anim. Welf. 1 (1992) 235- 247.

[15] M.J. Gentle, V.L. Tilston, Nociceptors in the legs of poultry: implications for potential pain in preslaughter shackling, Anim. Welf. 9 (2000) 227-236.

[16] L.E. Goehler, T.E. Finger, Visceral afferent and efferent columns in the spinal cord of the teleost, Ictalurus punctatus, J. Comp. Neurol. 371 (1996) 437-447.

[17] H.O. Handwerker, F. Anton, P.W. Reeh, Discharge patterns of different cutaneous nerve fibres from the rat's tail during prolonged noxious mechanical stimulation, Exp. Brain Res. 65 (1987) 493-504.

[18] P. Haupt, W. Janig, W. Kohler, Response pattern of visceral afferent fibers, supplying the colon, upon chemical and mechanical stimuli, Eur. J. Physiol. 398 (1983) 41-47.

[19] N. Iwahori, T. Kawawaki, J. Baba, Neuronal organisation of the spinal cord in the red stingray (Dasyatids akajei: Chondrichthyes), J. Brain Res. 39 (1998) 103- 116.

[20] M. Kavaliers, T.S. Perrot-Sinal, D.C. Desjardins, S.K. Cross-Mellor, J.P. Wiebe, Antinociceptive effects of the neuroactive steroid, 3-alphahydroxy-5 alpha-pregnan-20-one and progesterone in the land snail, Capaea nemoralis, Neuroscience 95 (2000) 807- 812.

[21] M.C. Kuhajda, B.E. Thorn, M.R. Klinger, N.J. Rubin, The effect of headache pain on attention (encoding) and memory (recognition), Pain 97 (2002) 213- 221.

[22] T. Kumazawa, K. Mizumura, Thin-fibre receptors responding to mechanical, chemical and thermal stimulation in skeletal muscle of the dog, J. Physiol. 273 (1977) 179-194.

[23] T. Kumazawa, K. Mizumura, Chemical responses of polymodal receptors of the scrotal contents of dogs, J. Physiol. 299 (1980) 219-230.

[24] E. Lang, A. Novak, P.W. Reeh, H.O. Handwerker, Chemosensitivity of fine afferents from the rat skin in vitro, J. Neurophysiol. 63 (1990) 887-901.

[25] R.B. Leonard, Primary afferent receptive field properties and neurotransmitter candidates in a vertebrate lacking unmyelinmated fibres, Prog. Clin. Res. 176 (1985) 135-145.

[26] Y. Liang, S. Terashima, Physiological properties and morphological characteristics of cutaneous and mucosal mechanical nociceptive neurons with A-y peripheral axons in the trigeminal ganglia of crotaline snakes, J. Comp. Neurol. 328 (1993) 88-102.

[27] M. López deArmentia, C. Cabanes, C. Belmonte, Electrophysiological properties of identified trigeminal ganglion neurons innervating the cornea of the mouse, Neuroscience 101 (2000) 11091115.

[28] P.G.M. Luiten, The central projections of the trigeminal, facial, and anterior lateral line nerves in the carp (Cyprinus carpio L.), J. Comp. Neurol. 160 (1975) 399- 418. 
[29] B. Lynn, The fibre composition of cutaneous nerves and the classification and response properties of cutaneous afferents, with particular reference to nociception, Pain Rev. 1 (1994) 172-183.

[30] G. Matthews, W.O. Wickelgren, Trigeminal sensory neurons of the sea lamprey, J. Comp. Physiol., A Sens. Neural Behav. Physiol. 123 (1978) 329- 333.

[31] I. Merchenthaler, J.L. Maderdrut, G. Lazar, J. Gulyas, P. Pertrusz, Immunocytochemical analysis of proenkephalin-derived peptides in the amphibian hypothalamus and optic tectum, Brain Res. 416 (1987) 219- 227.

[32] J.G. New, R.G. Northcutt, Primary projections of the trigeminal nerve in two species of sturgeon: Acipenser oxyrynchus and Scaphirhynchus platorynchus, J. Morphol. 182 (1984) 125- 136.

[33] R.G. Northcutt, Experimental determination of the primary trigeminal projections in lampreys, Brain Res. 163 (1979) 323-327.

[34] R.G. Northcutt, Evolution of the telencephalon in nonmammals, Annu. Rev. Neurosci. 4 (1981) 301-350.

[35] A. Reiner, The distribution of proenkephalin-derived peptides in the central nervous system of turtles, J. Comp. Neurol. 259 (1987) 65- 91.

[36] A. Reiner, H.J. Karten, N.C. Brecha, Enkephalin-mediated basal ganglia influences over the optic tectum: immunohistochemistry of the tectum and lateral spiriform nucleus in pigeon, J. Comp. Neurol. 208 (1982) 37-53.

[37] A. Reiner, R.G. Northcutt, An immunohistochemistry study of the telencephalon of the African lungfish, Protopterus annectens, J. Comp. Neurol. 256 (1987) 463-481.

[38] I. Rodríguez-Moldes, M.J. Manso, M. Becerra, P. Molist, R. Anadón, Distribution of substance Plike immunoreactivity in the brain of the elasmobranch Scyliorhinus canicula, J. Comp. Neurol. 335 (1993) 228- 244.

[39] M. Ronan, The sensory trigeminal tract of Pacific hagfish. Primary afferent projections and neurons of the tract nucleus, Brain Behav. Ecol. 32 (1988) 169- 180.

[40] J.A. Schulman, T.E. Finger, N.C. Brecha, H.J. Karten, Enkephalin immunoreactivity in Golgi cells and mossy fibres of mammalian, avian and teleost cerebellum, Neuroscience 6 (1981) 2407-2416.

[41] R. Simantov, M.J. Kuhar, G.R. Uhl, S.H. Snyder, Opioid peptide enkephalin: immunohistochemical mapping in rat central nervous system, Proc. Natl. Acad. Sci. U. S. A. 74 (1977) 2167-2171.

[42] L.U. Sneddon, Anatomical and electrophysiological analysis of the trigeminal nerve in a teleost fish, Oncorhynchus mykiss, Neurosci. Lett. 319 (2002) 167-171.

[43] L.U. Sneddon, Trigeminal somatosensory innervation of the head of the rainbow trout with particular reference to nociception, Brain Res. 972 (2003) 44- 52.

[44] L.U. Sneddon, The evidence for pain perception in fish: the use of morphine as an analgesic, Appl. Anim. Behav. Sci. 83 (2003) 153-162.

[45] L.U. Sneddon, V.A. Braithwaite, M.J. Gentle, Do fish have nociceptors: evidence for the evolution of a vertebrate sensory system, Proc. R. Soc. Lond., B 270 (2003) 1115- 1122. 
[46] L.U. Sneddon, V.A. Braithwaite, M.J. Gentle, Novel object test: examining pain and fear in the rainbow trout, J. Pain 4 (2003) 431-440.

[47] P.J. Snow, G.M.C. Renshaw, K.E. Hamlin, Localization of encephalin immunoreactivity in the spinal cord of the long-tailed ray Himantura fai, J. Comp. Neurol. 367 (1996) 264-273.

[48] K. Toda, N. Ishii, Y. Nakamura, Characteristics of mucosal nociceptors in the rat oral cavity: an in vitro study, Neurosci. Lett. 228 (1997) 95-98.

[49] E. Vecino, P. Ekstrom, S.C. Sharma, Enkephalin-like immunoreactive cells in the mesencephalic tegmentum project to the optic tectum in Salmo gairdneri and Salmo salar, Cell Tissue Res. 264 (1991) 133- 137.

[50] E. Vecino, C. Piňuela, R. Arévalo, J. Lara, J.R. Alonso, J. Aijón, Distribution of enkephalin like immunoreactivity in the central nervous system of the rainbow trout: an immunocytochemical study, J. Anat. 180 (1992) 435- 453.

[51] M. Whitear, The question of free nerve endings in the epidermis of lower vertebrates, Acta Biol. Hung. 34 (1983) 303-319.

[52] S. Willenbring, C.W. Stevens, Thermal, mechanical and chemical peripheral sensation in amphibians: opioid and adrenergic effects, Life Sci. 58 (1996) 125-133. 